\title{
Experiences with the Export of Education in Health Sciences from Denmark to Saudi Arabia
}

\author{
Arja R. Aro1 ${ }^{*}$, Leena Eklund Karlsson'1, Anne Leena Ikonen', Maria Palianopoulou1, Jesper Bo Nielsen² \\ ${ }^{1}$ Unit for Health Promotion Research, Department of Public Health, University of Southern Denmark (SDU), Esbjerg, Denmark \\ ${ }^{2}$ Department of Public Health, University of Southern Denmark, Odense, Denmark \\ Email: *araro@health.sdu.dk
}

How to cite this paper: Aro, A. R. Karlsson, L. E., Ikonen, A. L., Palianopoulou, M., \& Nielsen, J. B. (2018). Experiences with the Export of Education in Health Sciences from Denmark to Saudi Arabia. Creative Education, 9, 819-830.

https://doi.org/10.4236/ce.2018.96060

Received: March 25, 2018

Accepted: May 8, 2018

Published: May 11, 2018

Copyright $\odot 2018$ by authors and Scientific Research Publishing Inc. This work is licensed under the Creative Commons Attribution International License (CC BY 4.0). http://creativecommons.org/licenses/by/4.0/

\section{Open Access}

\begin{abstract}
Background: Exports of entire educational programs from countries with established universities to other countries are increasing rapidly. Scant literature exists on education exports and related educational and pedagogical knowledge transfer. Evidence in this area helps us to develop better and more cost-effective future export programs, render knowledge transfer more efficiently and enhance intercultural learning in general-all important in the current globalized world. Aim: To share the experiences and lessons learned during the educational export project of two Bachelor of Science programs in health sciences from a Danish university to a newly established Saudi Arabian university. Methods: There were two contract periods: one of 4.5 years and another 1-year extension. An accredited program from Denmark was exported with the goal of gradually transferring the knowledge of the exporting staff to the local staff. Teams of one senior and two juniors traveled from the exporting university to the receiving university to deliver courses lasting 4 weeks each. Implicit knowledge comes from the personal experiences of the authors in the preparation, collaboration, administration, management and teaching of the two BSc programs. Explicit, written data come from the evaluation reports, for which 24 students and 31 staff members were interviewed, and from a review of document filing and administrative course material. Analysis was conducted based on the Neville and Warren theory of knowledge transfer in educational settings and using SWOT analysis. Analysis and Conclusion: Opportunities for knowledge transfer were not fully implemented; however, during the contract years, exchange and collaboration between the staff groups increased. The successful and well-received education export with sustainable knowledge transfer requires thorough and collaborative preparation and needs-based implementation. Learning to know each other's working culture and creating mutual trust and acceptance take time and readiness to exchange expectations, views and experiences on equal footing.
\end{abstract}




\section{Keywords}

University, Education, Export, Health Science, Knowledge Transfer, Culture

\section{Background: Education Export and Knowledge Transfer}

The export of entire education programs from countries with established universities to other countries is increasing rapidly. These programs have grown in accordance with the numbers of students traveling abroad to complete their degree studies at established universities and, in general, with globalization. Traditionally, the UK, Australia and the US have been most active in attracting foreign students with around half a million foreign students registered, and for those countries, this sector is an important income source (ICEF Monitor, 2017; Universities UK, n.d.; The Editors of Encyclopedia Britannica, n.d.). More recently, Nordic countries that are leading societal innovations in Europe have entered the education export arena, particularly Finland. Education export has been defined as including "all business activities based on education; the educational system, transfer of knowledge that creates products or services that a foreign party pays for" (Ministry of Education and Culture, 2017).

Students traveling to another country must adjust to the foreign culture, social environment, manners of teaching and learning and working traditions. Most students, because of their age, are single and thus travel without their families. When returning to their home countries, they are likely to bring along learned perspectives, culture and work ethics. Conversely, when exporting an entire curriculum from one country/culture to another, somewhat different challenges must be addressed. First, the curriculum may require adjustments for the level and contents of teaching and teaching methods. Second, to collaborate, the exporting teaching staff must adjust to local university regulations, codes of conduct and work ethics; be accepted; and learn the manners, expectations and motivations of the local staff and students. All of this comes in addition to their own adjustment to the local culture and social environment. Further, the exporting staff members may also have to set aside or postpone their job tasks at home for longer periods and in many cases, be separated from their families.

Little scientific literature exists on education export and related educational and pedagogical knowledge transfer, which differs from the knowledge transfer literature related to research. In general, knowledge transfer is a term used to encompass a very broad range of activities to support mutually beneficial collaborations between universities, businesses and the public sector (University of Cambridge, n.d.). According to classical theories of knowledge transfer in educational settings, knowledge transfer can be examined using: 1) the research, development and diffusion model; 2) the problem-solving model; 3) the linkage model; and 4) the social interaction model (Neville \& Warren, 1986). The research, development and diffusion model seeks to advance knowledge by active- 
ly pushing it on the recipients; thus, there is no real interaction between knowledge producers and recipients. The problem-solving model expects that the knowledge users (e.g., the recipient teachers) themselves are responsible for identifying and formulating their needs for knowledge transfer. The linkage model combines the first two but builds upon relations between certain persons and systems (such as the knowledge providers and recipients within the learning loop). In the social interaction model, knowledge producers and recipients repeatedly interact (on an equal footing) and co-produce knowledge and know-how (Neville \& Warren, 1986). The social interaction model is often observed when partners on equal levels exchange knowledge and educational experiences.

It is certainly time to study the growing field of education export and knowledge transfer. Evidence in this area can help us develop better and more cost-effective export programs, render knowledge transfer more efficient and enhance inter-cultural learning in general, all of which are important in the current globalized word.

\section{Aim}

This paper describes the educational export experience of two Bachelor of Science programs in health sciences from a Danish University (the exporting university) to a newly established Saudi Arabian University (the recipient university). The objective here is to share the experiences and lessons learned so that they may be used by others for further development of this growing educational market.

\section{Methods}

Both implicit and explicit knowledge was used. Implicit knowledge came from the experiences of the authors in the preparation, collaboration, administration, management and teaching in the two BSc programs (Health Education and Promotion and Epidemiology) of the between-university contracts from April 2012 to August 2017. The analysis process was heuristic: the "self" of the researcher was constantly present, allowing creative self-processes of knowing and self-discoveries (Moustakas, 2011). The explicit knowledge, i.e., written data, came from three evaluation reports produced by the exporting university: mid-term and final reports of the initial 4.5-year contract and a final report following the 1-year contract extension. The data gathered for the reports included 24 student interviews of all student cohorts during the contract periods at the receiving university and 31 staff interviews of both the receiving and exporting university staff. The student interviews were done by two of the co-authors (ARA and ALI) and the staff interviews by one (ARA). Focus group interviews were done (anonymously) in groups of 2-8 students, whose teachers had been asked to randomly select students for these interviews; all staff members actively involved in teaching when the mid-term and final report data were collected, 
were interviewed individually and when staff members were not on-site, via email. The topics of interviews among the students included issues such as satisfaction and feedback on teaching level, study load, and methods, exams, availability and relevance of the study material plus the organization of teaching and advice received on curriculum and degree issues. Interview topics among the staff covered experiences with the collaboration between the exporting and recipient university, lessons learnt, use and usefulness of teaching material plus in the last year of collaboration satisfaction with the two competence development workshops offered. The interviewees were informed, and they accepted that the data gathered would be used as a component of quality assurance reporting of the education export of the Danish university.

In addition, an examination of the document filing and administrative materials for educational courses related to the two programs of the receiving university was conducted.

\section{The Contract Agreement}

Because of a short business negotiation phase, the teaching was brought to Saudi Arabia from the Danish culture and context on short notice, allowing for only minor adjustments to the course descriptions (defining the teaching topics and major student reading) of the previously accredited Danish BSc of Public Health Program that was exported. This approach, on the one hand, ensured that the recipient university received a fully accredited international education program. However, predefined course descriptions did not allow the course contents and pedagogy to be sufficiently tailored to the local context and culture.

The agreed-upon central mechanism for facilitating knowledge transfer was co-teaching with the percentage of the recipient university's teaching share gradually increasing. The idea was to provide learning opportunities for the local teachers in this manner. It was agreed that the first cohort would be taught $100 \%$ by the exporting university with the assistance of the local teachers; the second cohort would be taught $66 \%$ by the exporting university, and the third cohort, $20 \%$. The exporting team, generally comprising one senior and two junior teaching assistants per course, remained on the payroll of their home university in Denmark and visited Saudi Arabia to teach mostly 4-week-long courses. The number of teachers simultaneously on site from the exporting university varied from 3 to 12 depending on the number of student cohorts and their courses running concurrently in the two programs. The contract was based on exporting senior staff members with full professor and associate professor qualifications with wide teaching and research experience, including international experience. This would enable knowledge transfer in teaching and academic work from the experienced staff to the locally hired, more junior staff. In addition, a professor and an associate professor from the exporting university were formally nominated as academic supervisors and quality overseers of the two programs. 


\section{Implementation of Teaching}

\subsection{The $1^{\text {st }}$ Semester: Pioneer Work}

The first exporting team of two seniors and two juniors arrived in Saudi Arabia one week before the beginning of the semester. At this point, the local dean reported that only a few students had selected the two programs as their first option; however, one week later, 67 students were enrolled in the two programs. These students of the first cohort were a heterogeneous group with varying levels of English language and other study skills. Many of the students expected to learn about medical topics, indicating that there was little prior awareness among the new students regarding the contents of the two programs in which they had enrolled. However, the students were thrilled to begin their studies and warmly welcomed the foreign team.

The exporting team began to teach before any administrative structure or guidance had been developed for the new faculty in the new university. In the first semester, the exporting team functioned as pioneers, defining (by trial and error based on daily experiences) the level of teaching, actual course content, practical examples and necessary templates for administrative documents. Only one local junior academic staff member had been hired-primarily to support the dean-for the first semester. Thus, there was no local senior-level counterpart for the teaching team from Denmark with whom to negotiate or exchange knowledge when tailoring the teaching. However, the local dean and the junior were quite involved in general issues concerning teaching and local administrative practices and consistently supported the teachers.

\subsection{From the $2^{\text {nd }}$ Semester Onwards}

More staff members were hired at the receiving university, including Middle Eastern PhD holders, to function as local study coordinators; further, a department head was hired as well as a new junior who knew the Danish culture and could thus function as the contact person to the Danish team; all of these staff members were Arabic-speaking. With the new staff, new administrative practices began to be developed, partially replacing the ones developed ad hoc for the previous semester. Development and re-development of administrative practices such as exam rules and grade registration occurred as the program progressed. Consistent with local administrative practices, these changes were communicated only orally (among Arabic-speaking staff) without written documentation in English. Changes were also sometimes made retrospectively; thus, documentation needed to be redone several times according to the new guidelines.

With new annual student cohorts, including an extra cohort beginning their studies in the $2^{\text {nd }}$ semester, all local teaching staff were required to run the courses; thus, it was not possible to implement the planned and expected co-teaching and ensuing knowledge transfer.

The differences in academic backgrounds and levels and different culture-related traditions and customs in education provided immediate challenges 
to collaboration. Another challenge was the perceived informal visitor role of the exporting staff compared with the locally hired staff with formal teaching contracts. For example, details of the contract in such areas as the academic supervisor and quality supervisor roles of the exporting staff and the objectives of the planned knowledge transfer were not communicated by the recipient university to its local staff. Thus, both staff groups felt responsible for the teaching programs and their organization. In addition, the exporting university-nominated study leader of the programs and locally nominated study coordinators had partially overlapping roles and tasks without systematic coordination or any discussion of potential collaboration.

Changes in leadership at the local university brought its own challenges; e.g., during the 5.5-year education export project, there were three different deans responsible for the programs.

Challenges culminated when the first student cohort began their BSc thesis-writing courses (managed completely by the exporting university) because no written guidelines were circulated on the new process of ethics clearance or thesis synopsis evaluation. The exporting university staff functioned using established practices and quality criteria from their own university; the local staff expressed the need to supervise and correct the work of the senior exporting staff.

On the administrative level, the exporting university professor had an accepted and visible role in conducting the evaluations of the programs, and her collaboration with the department head and international office staff was quite effective and fruitful, although her role primarily addressed contractual issues and planning for the future rather than operative level teaching issues and problems encountered.

\subsection{The 1-Year Extended Contract Period}

The recipient university offered a 1-year extension of the contract because it had not been able to hire new competent staff to take over all of the teaching responsibilities. Some changes in terms were deemed necessary for this new 1-year contract. Both sides acknowledged that the co-teaching approach that had been followed during the previous contract period-the joint teaching of the courses from two different staff groups, one from the exporting university and the other from the receiving university-was too challenging. Thus, it was agreed that the two universities would divide the courses between them, and each university ran their courses independently except for two courses, which were taught half by the exporting university and half by a local junior staff member. In addition, attempts were made to create more structure and transparency for collaboration, such as organizing regular teachers' meetings each semester and creating a Steering Group for the programs with representatives from both universities. Further, two "train-the-trainers" workshops were planned and implemented by the exporting university staff for the local teaching staff to develop their competences: one on Active Learning Methods and the other on Qualitative Research 
Methods.

\section{Analysis and Discussion}

The collaboration, particularly in the beginning, largely resembled push-based knowledge transfer (Model 1/diffusion). The idea of co-teaching and the gradual transfer of teaching from the exporter university was acknowledged and respected by the executive level of the recipient university; however, the transfer was not introduced or discussed on the day-to-day operative level of teachers. One example of different expectations was that the local teachers on several occasions referred to using the slides and reading material prepared by the exporting staff as a knowledge transfer practice. As mentioned above, before initiating the collaboration or in the beginning of the collaboration, there were no operative level counterparts on the recipient side to discuss the needs or demands of the teaching collaboration.

In terms of the problem-solving model (Model 2), the challenge was that even if the local university leadership expected knowledge transfer, among some locally hired teaching staff, there was a lack of an explicitly expressed need for knowledge transfer and a rather negative attitude towards it. In the evaluation interviews, some of the local teaching staff members emphasized that they (with a foreign $\mathrm{PhD}$ degree) had at least the same competences and experiences as the exporting staff of professors and associate professors. This attitude indicated a lack of mutual understanding or justification of the academic credentials of the two groups. The locally hired staff understood and explicitly referred to knowledge transfer as the teaching material, such as slides and exercises, prepared and handed over by the exporting university to the local staff. Conversely, the exporting university understood the knowledge transfer to be transferring knowledge from one teacher to another: expertise, learning together, sharing goals, solving problems, and distributing knowledge in teaching.

Consistent with the contractual agreement, the courses for the first student cohort were taught $100 \%$ by the exporting university. The following cohorts were taught $66 \%$ vs. $34 \%$ and $20 \%$ vs. $80 \%$ by the exporting vs. the local university, respectively. When dividing the courses among themselves, the university teams mostly worked in silos, taking care of their own teaching. However, most junior local staff members were keen to learn co-teaching whenever possible and obtain career consulting from the exporting team. One of the locally hired juniors responsible for $34 \%$ of the teaching followed the entire course and participated in all group work tasks in addition to her own teaching share.

For co-teaching and knowledge exchange, it would have been beneficial to have access to one another's teaching material. However, the teaching material of the local staff, even the material initially created by the exporting team, was deemed "private and confidential". This situation did not encourage mutual feedback on teaching methods and experiences.

Executives at the highest level at the local university appeared to share the 
perception of knowledge transfer with the exporting university; the middle administrative level appeared to have more mixed expectations. The attempts to discuss and clarify knowledge transfer and other challenges collaboratively at teachers' meetings were not successful "because of the prevailing meeting traditions that do not allow open discussions" (as expressed by some of the interviewees). Further, written evaluation reports and other documents prepared by the exporting university were not circulated among the local staff-and the exporting university was not allowed to directly circulate any of their written materials. This is an example of differences in the university and teaching cultures of which neither of the two universities was probably aware; this further hampered the sharing of proper feedback between the teams.

The local staff expressed being too immersed in their own teaching to allow any closer collaboration. Thus, organizing the teaching work did not enhance possibilities for knowledge transfer. On a daily level, office hours of the local staff were another hurdle for knowledge transfer, as mentioned by the exporting university staff; the majority of the local staff left their offices often around noon or $1 \mathrm{pm}$. The exporting university staff were teaching from 08.00 to noon or until 14.30; thus, after their teaching hours, there were limited possibilities for interaction or knowledge exchange between the teams.

The linkage model (Model 3) was not strongly represented in the collaboration since the exporting and recipient university staff groups scarcely got to know one another well enough. In addition, focus on knowledge transfer was interpreted differently (as mentioned above) by the exporting team and the local team.

Social interaction (Model 4) gradually increased during the contract years when the exporting and recipient staff groups began to know one another better. In addition, more social gatherings were arranged between the local junior staff and the exporting team, which further strengthened the relationships between exporting team and the local juniors.

During the contract years, some teachers from the exporting university came regularly to teach courses, and some junior exporting team members worked on-site for full semesters. In the evaluation interviews, the local staff stated that one of the primary obstacles to building knowledge transfer interaction was that the senior exporting staff did not stay the full time in Saudi Arabia. However, a lack of written administrative guidelines rendered it difficult to follow the development and agreed-upon practice in the faculty.

As explained above, to further enhance knowledge transfer, in the 1-year extension of the contract, specific train-the-trainer workshops for teacher competence development were organized by the exporting university. These workshops, which comprised 9 and 7 sessions, essentially increased social interaction between the two universities. These workshops were built on exchanging ideas and a non-threatening atmosphere; it was possible to assess the beginning level of competences, which enabled needs-based learning. The participants evaluated 
both workshop series as extremely relevant and good learning experiences. Earlier, only a few junior local staff members had been openly eager to learn from the exporting staff in the normal teaching of the courses.

Although knowledge transfer in actual teaching was not fully implemented, in their evaluation interviews, several local teachers expressed that they had learned a lot from the exporting team, particularly regarding the systematic and transparent filing system and organizing the teaching and the material. Thus, implicit knowledge transfer occurred, particularly in the later years of collaboration; according to Reagans and McEvily (2003), the transfer of implicit knowledge requires a stronger network or connection than the transfer of explicit knowledge. Certainly, our collaboration also enabled the transfer of explicit knowledge such as methods and contents of teaching; we could, however, not confirm this because of a lack of co-teaching and access to teaching materials developed by the local staff.

The student interviews, particularly of those cohorts the exporting university was teaching $66 \%-100 \%$, expressed their appreciation for improving their academic skills, becoming more international, the wide-ranging research and experience-based teaching, which also made them independent, critical, motivated knowledge seekers and appliers. Most students also liked the hybrid model of problem-based learning used in the teaching (Husain, 2011) because it enabled them to work and discuss in groups, which was new to them. The feedback received from the first-year student interns supported the appreciation of the students themselves. Conversely, some students preferred local Arabic-speaking teachers both because of their using the Arabic language in teaching and because of their more familiar teaching style.

\section{SWOT Analysis of the Collaboration}

Strengths: Education export across cultures taught the partners a lot about one another's manners of working, teaching, learning, interacting, and functioning in knowledge transfer. Naturally, there was also an economic perspective, which provided resources for the exporting university. On the student side, knowledge transfer appeared to be valuable and appreciated both by the students themselves and their internship places among the first two student cohorts, who were taught fully or mostly by the exporting staff and who finished their studies during the contract time. On the administrative side and on an individual level, some development of knowledge transfer began to appear in the last two years of the collaboration; examples include increasing consultation meetings with the department head and secretary to develop administrative practices.

Weaknesses: A recipient university without established administrative practices and with a lack of competent staff could not provide a strong foundation for collaboration in the beginning. Thus, the two groups worked primarily in silos. Further, the lack of a proper pre-contract preparation period with needs assessment, competence mapping, and social networking to build knowledge 
transfer created difficulties. For the exporting university, the collaboration was rather costly in terms of using high-level academic resources in attempting to develop the basics for the new BSc education in a foreign context. Although the teaching programs were officially run in English, Arabic was the administrative language and mother tongue of the locally hired staff; thus, foreigners with no or insufficient Arabic skills did not feel included in the largely oral administrative practices at the local university.

Opportunities: The export contract provided an opportunity for knowledge transfer for the academic staff on both sides. This opportunity could not be fully exploited. In addition to the actual contractual teaching activities, some research collaboration with publications as output provided opportunities to both local academic staff and to some students to publish papers based on the BSc thesis topics.

This type of collaboration has potential for opportunities in competence development, teaching and research collaboration in addition to expanding inter-cultural understanding and collaboration. Junior staff members of the exporting university in particular, who stayed longer periods on-site, had an opportunity to learn to teach in a different cultural context. For the students, this type of education export enabled them to stay in their home country while receiving an international education.

Threats: Differing expectations and readiness levels for collaboration in the two universities certainly created challenges to successful collaboration. In addition, the lack of thorough cultural knowledge and an understanding of different learning styles (for example the "feeling and reflecting" learning style in the Middle East vs. the "thinking and action" learning style of the Anglo-North European region) (Yamazaki, 2005) was a deficit. Further, the export contract being a business contract, the exporting staff felt that they were sometimes perceived as "guest workers" with lower status than the local staff on the payroll irrespective of their higher academic credentials and wider academic experience.

\section{Recommendations for Similar Education Export Projects in the Future}

To avoid the knowledge transfer push from experts coming from different contexts, more collaborative contract planning would be beneficial. Needs and competences, cultural learning principles and the personality fit of both exporters and recipients should be mapped, and the knowledge transfer should answer to local needs (Räsänen, 2012). Smooth and continuous communication between the university teams but also on site among the day-to-day teaching and administrative staff is required. Linkage and social interaction must be developed in the planning, implementing and evaluating of all actions, including competences and the career development of both sides. Specifically, in knowledge transfer projects, the objectives of the transfer must be communicated and agreed upon at different levels of the recipient university. In addition, if several exporting 
universities are working on the same site, collaboration among them could enhance cultural adaptations, knowledge exchange between these groups and more efficient use of resources.

Potentially, train-the-trainer seminars or workshops with different administrative and teaching staff from both contract partners would be helpful to achieve equal footing and facilitate mutual understanding instead of a fixation on the roles of knowledge transfer providers and recipients. These occasions would be necessary in different phases of the contract and collaboration from planning and implementation to evaluation. Students should be an integral component of the organized seminars and workshops. Naturally, these means can be used only when the main structures (and students) of the recipient university are already in place, which was not the case when this specific collaboration was initiated.

Another lesson learned is that it takes time, effort and staff continuity from leadership to regular staff to develop administrative and confidence-based structures and trust to support knowledge transfer. To obtain the full value of the investment, the recipient university should have clear and ready administrative structures in place as well as competent staff members who have been introduced to and motivated by the collaboration. Conversely, the exporting university should invest time and resources in the contract preparation phase and if possible, also meet and get to know local staff members, their needs and their competences. These conditions are naturally difficult to achieve if the recipient university is new and only developing its systems.

All in all, both sides of this collaboration expressed useful lessons learned, and both sides also expressed regret that the investment in the collaboration and particularly the positive experiences of the final year of the contract could not be continued because of the completion of the collaboration.

Recent frameworks used in education export have tended more towards business models for selling services (Huovinen, 2011) than frameworks for knowledge transfer across cultures. Clearly, there is a need for framework development in the field to increase understanding of the processes and develop more cost-effective and culturally sensitive educational knowledge transfer programs and tools. In addition, this type of international, intercultural collaboration has value beyond business, such as supporting the development and empowerment of the recipients.

\section{Conclusion}

This paper provides experiences and lessons learnt in the 5.5 years of the export of education from Denmark to Saudi Arabia. As a report on collaboration between only two universities in addition to the Saudi Arabian university being in its initial phase of development, the paper has its limitations and cannot give a general picture of education export between countries and cultures.

Bearing this in mind, we can conclude that the successful and well-received 
education export with sustainable knowledge transfer requires thorough and collaborative preparation and needs-based implementation. Learning to know each other's working culture and creating mutual trust and acceptance take time and readiness to exchange expectations, views and experiences on equal footing.

\section{Conflict of Interest}

Eklund Karlsson L, Ikonen AL, and Palianopoulou M received salaries from the teaching contract between the Danish and Saudi Arabian universities.

\section{References}

Huovinen, S. (2011). Export of Education. Haaga-Helia. https://www.theseus.fi/bitstream/handle/10024/33602/Master\%20Thesis\%20-\%20Expo rt\%20of\%20Education $\% 20-\% 20$ Huovinen.pdf?sequence=1\&isAllowed =y

Husain, A. (2011). Problem-Based Learning: A Current Model of Education. Oman Medical Journal, 26, 295. https://doi.org/10.5001/omj.2011.74

ICEF Monitor. (2017). Australian Education Exports Approaching AUD\$29 Billion. http://monitor.icef.com/2017/10/australian-education-exports-approaching-aus29-billi on/

Ministry of Education and Culture. (2017). Marianne Huusko-A Trailblazer in Education Export.

http://minedu.fi/en/article/-/asset_publisher/marianne-huusko-koulutusviennin-ladun avaaja

Moustakas, C. (2011). Research Design and Methodology. In Heuristic Research: Design, Methodology, and Applications (pp. 38-58). Thousand Oaks: SAGE Publications, Inc.

Neville, J., \& Warren, B. (1986). The Use and Dissemination and Innovative Knowledge. The Journal of Product Innovation Management, 3, 27-135.

Räsänen, E. (2012). Education Export as a Form of Knowledge Transfer: The Potential of Finnish Education Export in Chile. Turun kauppakorkeakoulu.

Reagans, R., \& McEvily, B. (2003). Network Structure and Knowledge Structure: The Effects of Cohesion and Range. Administrative Science Quarterly, 48, 240-267. https://doi.org/10.2307/3556658

The Editors of Encyclopedia Britannica. U.S. Higher Education as an Export. https://www.britannica.com/topic/U-S-Higher-Education-as-an-Export-1891748

Universities UK. The Voice of Universities. International Students Now Worth £25 Billion to UK Economy-New Research. http://www.universitiesuk.ac.uk/news/Pages/International-students-now-worth-25-bill ion-to-UK-economy---new-research.aspx

University of Cambridge. What Is Knowledge Transfer? http://www.cam.ac.uk/research/news/what-is-knowledge-transfer

Yamazaki, Y. (2005). Learning Styles and Typologies of Cultural Differences: A Theoretical and Empirical Comparison. International Journal of Intercultural Relations, 29, 521-548. https://doi.org/10.1016/j.ijintrel.2005.07.006 